\title{
NOVAS TECNOLOGIAS APLICADAS AO ENSINO CONSTRUTIVISTA: UMA APROXIMAÇÃO À VISÃO DA INTEL PARA A EDUCAÇÃO
}

\author{
Thiago Garcia Martins ${ }^{1}$ \\ Geisiane Françosa Nogueira²
}

MARTINS, T. G.; NOGUEIRA, G. F. Novas tecnologias aplicadas ao ensino construtivista: Uma aproximação à visão da intel para a educação. EDUCERE - Revista da Educação, Umuarama, v. 17, n. 1, p. 131-144, jan./jun. 2017

RESUMO: O presente trabalho apresenta um estudo comparativo dos conceitos sobre o ensino construtivista e do vídeo intitulado 'Project Bridge - A visão da Intel para Educação'. Muito se discute sobre a inserção de novos aparatos tecnológicos dentro de sala de aula e como podem ser utilizados a favor das metodologias educacionais. O vídeo exemplifica um processo de ensino construtivista tendo apoio das tecnologias educacionais sendo possível compreender como as tecnologias digitais podem ter um papel importante na educação das crianças, desde que seja utilizada com fins pedagógicos.

PALAVRAS-CHAVE: Construtivismo; Digital; Ensino; Tecnologia.

\section{NEW TECHNOLOGIES APPLIED TO CONSTRUCTIVE EDUCATION: AN APPROACH TO INTEL'S VISION FOR EDUCATION}

\begin{abstract}
The present work presents a comparative study on the concepts about constructivist teaching and the video entitled 'Project Bridge - Intel's vision for Education'. There is much discussion about the insertion of new technological devices inside the classroom and how they can be used in favor of educational methodologies. The video exemplifies a

DOI: https://doi.org/10.25110/educere.v17i1.2017.6288

${ }^{1}$ Doutorando em Comunicação e Linguagens (UTP), Mestre em Comunicação e Linguagens (UTP) e Pós-graduado em Administração de Marketing (UEL). Docente na Universidade Paranaense (UNIPAR). E-mail: thiago@prof.unipar.br

${ }^{2}$ Graduada em Tecnologia e Análises de Sistema pela Universidade Paranaense (UNIPAR). E-mail: geisianefnogueira@hotmail.com
\end{abstract}


constructivist teaching process with the support of educational technologies and it is possible to understand how digital technologies can play an important role in the education of children, provided it is used for pedagogical purposes.

KEYWORDS: Constructivism; Digital; Teaching; Technology.

\section{NUEVAS TECNOLOGÍAS APLICADAS A LA ENSEÑANZA CONSTRUCTIVISTA: UNA APROXIMACIÓN A LA VISIÓN DE LA INTEL PARA LA EDUCACIÓN}

RESUMEN: En este artículo se presenta un estudio comparativo de los conceptos de enseñanza constructivista y del vídeo intitulado 'Proyecto Puente - La visión de la Intel para la Educación’. Existe un debate acerca de la inclusión de nuevos dispositivos tecnológicos en el aula y cómo pueden ser utilizados a favor de las metodologías educativas. El vídeo ejemplifica un proceso de enseñanza constructivista con apoyo de tecnologías educativas, siendo posible entender cómo las tecnologías digitales pueden tener un papel importante en la educación de niños, desde que se use con fines pedagógicos.

PALABRAS CLAVE: Constructivismo; Digital; Enseñanza; Tecnología.

\section{INTRODUÇÃO}

Um assunto que vem sendo muito discutido são as novas tecnologias educacionais: como podem servir como apoio na educação de crianças e quais são as vantagens e as desvantagens para o aprendizado por meio da implantação da tecnologia nas escolas. As metodologias educacionais foram largamente discutidas do ensino-aprendizagem até ao construtivismo e, atualmente, como as novas tecnologias educacionais podem ser utilizadas com objetivos pedagógicos com a finalidade de educar.

É fato que há um crescente acesso às novas tecnologia, com introdução de aparelhos como celulares, tablets e computadores cada vez mais modernos, há um aumento no número de pessoas conectadas. Esse número também se reflete nas crianças, que cada vez mais cedo possuem celulares e acessam a internet.

Há, também, um esforço das empresas de tecnologia no suporte e desenvolvimento de ferramentas para a educação. A Intel, por exemplo, 
possui uma área em seu site oficial que traz informações que prometem apoio aos educadores. Segundo a Intel (2017), a tecnologia integrada efetivamente em sala pode envolver os alunos e ampliar seu potencial, desta forma, a organização oferece estudos de casos compartilhados, ferramentas e notícias sobre o tema em sua plataforma. A empresa também produziu um vídeo, intitulado 'Project Bridge - A visão da Intel para Educação’, um audiovisual publicado no canal da Intel no YouTube que ilustra alunos e professor utilizando de tecnologias em um projeto educacional.

O presente artigo tem como objetivo comparar, a partir de uma revisão de literatura, os conceitos de tecnologias educacionais no ensino interacionista-construtivista com o vídeo Project Bridge da Intel. Mesmo por se tratar de um vídeo de ficção, há a promessa da empresa de exemplificar os conceitos já estudados por teóricos da área, sendo esta a hipótese do presente artigo.

\section{O ENSINO E AS TECNOLOGIAS EDUCACIONAIS}

Mesmo com o avanço da tecnologia e as inúmeras fontes de informações, em que todas as pessoas podem ter acesso através da internet, boa parte das escolas ainda utilizam do ensino tradicional. É um processo de ensino-aprendizagem, no qual há somente as interações entre professor e aluno. Uma característica dessa relação no ensino tradicional é que o professor transmite o conteúdo como uma verdade a ser absorvida (LẼ̃O, 1999).

O ensino tradicional consiste na transmissão de conhecimentos aos alunos pelo professor, que detém o conhecimento. Os alunos recebem esse conhecimento com objetivo de memorizar o conteúdo e realizar os exercícios de forma disciplinada. Os recursos para este ensino são basicamente lousa, giz, livros e caderno, sendo que vem passando por transformações na atualidade.

Com o passar do tempo o ensino passou por várias mudanças: do ensino tradicional à construção do conhecimento. Pelo ensino construtivista, o conhecimento não é dado como algo pronto, terminado, mas construído pelo aluno por meio das interações com o meio físico e social (LEÃO, 1999).

Para Leão (1999), o aspecto metodológico construtivista se ba- 
seia em explicar os detalhes das técnicas utilizadas, justificar como chegou nessas técnicas, os objetivos em relação à aprendizagem e as consequências pedagógicas. Tendo como um de seus precursores Jean Piaget, a educação construtivista tem a premissa de levar os alunos a buscarem respostas a partir de seu próprio conhecimento e da interação com a realidade e os colegas. Assim, propõe que o aluno tenha uma participação ativa na própria aprendizagem, seja por meio da experimentação, discussão em grupos, pelo estímulo à dúvida e ao desenvolvimento do raciocínio.

Em relação à alfabetização de crianças, uma das críticas do ensino construtivista é a não utilização de um método para alfabetização (LEÃO, 1999), pois somente é aplicada uma técnica pedagógica não sendo questionado o motivo pelo qual a criança deve ser alfabetizada de tal forma. Além de que na alfabetização, as crianças não aprendem ao mesmo tempo, elas não possuem homogeneidade de conhecimento.

Nos dias atuais também é possível visualizar alguns casos práticos de novas tecnologias educacionais, como educação a distância, ambientes virtuais de aprendizagem (AVA), plataformas de gerenciamento de cursos, jogos e sites educacionais, entre outros. Estas tecnologias educacionais vêm ganhando força pela crescente utilização dos computadores e, principalmente, da internet.

Há escolas que usam de projetores, materiais multimídia e laboratórios de informática como apoio nas aulas e contribuindo para a inclusão digital do aluno. Mas, é importante lembrar do fato de que, ainda hoje no Brasil, a grande maioria das escolas públicas não possuem estrutura para usufruir de tais recursos, principalmente escolas ribeirinhas e escolas de difícil acesso.

As tecnologias educacionais se mostram uma grande aliada no ensino, pois podem possuir um baixo custo, além de existirem diversas plataformas gratuitas de ensino na internet, que podem ser utilizadas como apoio na educação. Um exemplo são os AVAs (Ambientes Virtuais de Aprendizagem), geralmente utilizados em educação a distância e treinamentos de colaboradores nas empresas. Esses ambientes possuem o conceito interacionista-construtivista (PINTO, et al, 2002), em que o conhecimento é construído pelo próprio aluno através de interações com outras pessoas, seguindo, assim, o princípio do ensino construtivista. 


\section{TECNOLOGIAS EDUCACIONAIS COMO APOIO NO ENSINO DE CRIANÇAS}

A tecnologia na educação das crianças e a estrutura de aprendizagem dos sites e programas educacionais, vem sendo discutidas no intuito de valorizar espaços que possibilitam a participação das crianças de forma ativa e voltada à educação, sem ser meramente a navegação por páginas e acesso a jogos.

As crianças são incentivadas em aprender, desde os primeiros meses de vida, por meio de ações desenvolvidas pelos próprios pais (desde conversar com a criança, cantar, bater palmas, entre outros). Com o início da alfabetização a tecnologia pode servir como apoio na aprendizagem. Carvalho (2014) afirma que o computador já pode ser utilizado como ferramenta de ensino, mesmo quando as crianças não sabem ler ou escrever. Assim, jogos e outras atividades no computador podem auxiliar para o exercício de estratégias e imaginação, favorecendo a aprendizagem das crianças.

A inclusão digital na infância, desde que sejam utilizadas com objetivo pedagógico definido, pode ser um meio de fácil aprendizagem. Por exemplo, as crianças podem aprender a desenhar, pintar e escrever, tudo isso desde que tenha conteúdo para aprendizagem, favoreçam a análise, a argumentação e a compreensão dos conteúdos (CARVALHO, 2014).

Os ambientes virtuais, como sites, devem ter boa navegabilidade e acessibilidade para auxiliar na aprendizagem das crianças. A faixa etária e o conteúdo do espaço virtual devem ser levados em conta para a construção de interfaces e ferramentas, possibilitando a interação no site e clareza de como isso ocorre, por meio de ícones ou mensagens para a facilidade no acesso.

O processo de ensino-aprendizagem, em que o professor passa o conhecimento aos alunos, pode ser enriquecido por meio do uso de novas tecnologias, passando a ter um relacionamento em que todos participam da aprendizagem, de forma que use o conceito construtivista e interacionista-construtivista. Os alunos devem se sentir à vontade com a tecnologia, mas o aprendizado tem que ser integrado aos componentes eletrônicos e os não-eletrônicos (SCHNEIDER, 2002).

A tecnologia na educação das crianças nas escolas promove uma 
inclusão digital, assim como a comunicação e o acesso à informação, servindo como instrumento de ensino pedagógico, melhorando o conhecimento e desempenho. É possível concordar que o apoio da tecnologia pode melhorar o sistema educacional. A adoção de novas tecnologias e recursos avançados pode trazer mais interações entre os alunos e o professor, além de possibilitar maior apoio ao docente despertando um maior interesse nos estudantes.

As ferramentas tecnológicas são aliadas do ensino e é possível aproveitar o melhor da internet para a educação das crianças. Com do uso de celulares, tablets e computadores pode-se ter uma interação com uma grande quantidade de atividades como jogos, quizzes, chat, entre outros, possibilitando aprender novos conceitos que vai desde matemática até artes. Schneider (2002) afirma que o aprendizado não deve ser somente com o uso das novas tecnologias, mas também continuar utilizando ferramentas não eletrônicas, possibilitando uma integração entre elas.

\section{A VISÃO DA INTEL PARA A EDUCAÇÃO}

O vídeo 'Project Bridge - A visão da Intel para Educação', publicado pela Intel no ano de 2013, traz uma representação de como a tecnologia pode ser utilizada dentro da sala de aula. O vídeo inicia com uma sala de aula com crianças de aproximadamente 11 anos de idade tendo o professor em frente à um quadro interativo (Figura 1).

Figura 1: formato da sala de aula

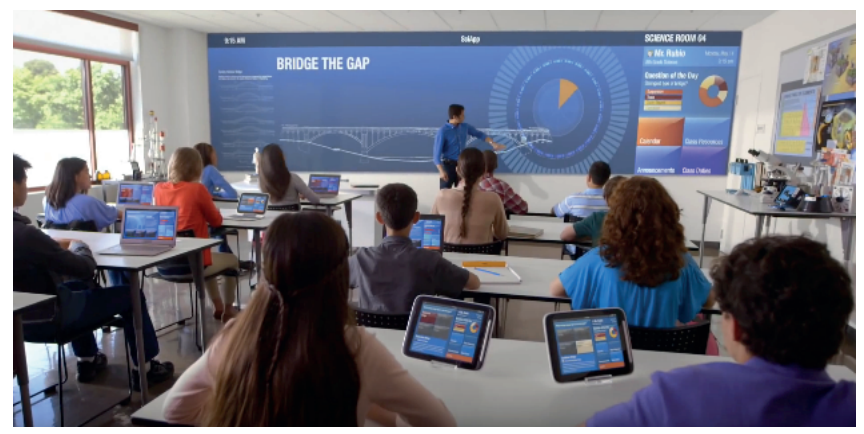

É possível perceber que o modelo de sala de aula representado 
não é muito diferente do tradicional. Com exceção das tecnologias atuais (lousa interativa, tablets e computadores), o formato da sala de aula é idêntico aos atuais - alunos sentados em fileiras, enquanto o professor explana em frente ao quadro.

Em um segundo momento, após a explicação sobre estilos de pontes, os alunos acessam conteúdos em seus dispositivos, vendo mais fotos e informações sobre o conteúdo passado. Enquanto isso, o professor monitora em seu tablet o desempenho de cada aluno, assim como sua evolução individual no projeto. É possível observar que há uma interatividade do ambiente virtual com o conhecimento adquirido do aluno. Como demostra a Figura 2, a aluna responde um quiz e sua porcentagem de compreensão aumenta progressivamente.

Figura 2: Quiz na aprendizagem

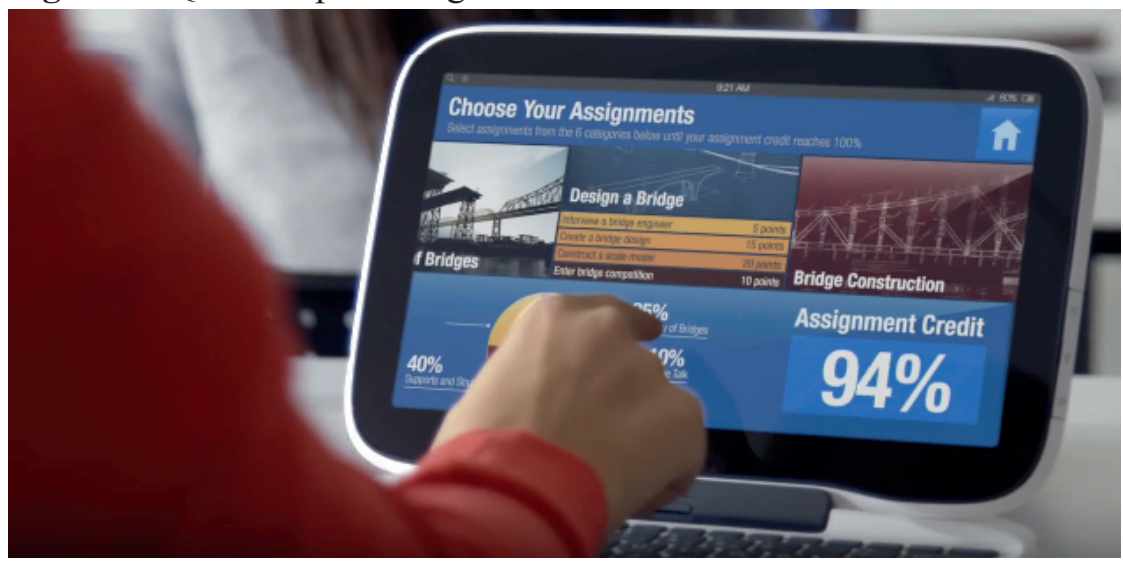

Em uma outra cena, a aluna está em casa desenvolvendo o projeto junto com seu pai, utiliza de tablets e computadores para dar adiantamento na construção do trabalho, como um dever de casa. Já em outro momento, de volta à sala de aula, professor e alunos interagem com um engenheiro de pontes em tempo real por vídeo conferência (Figura 3), onde o especialista tira dúvidas sobre os conteúdos. 
Figura 3: Vídeo-chamada com especialista

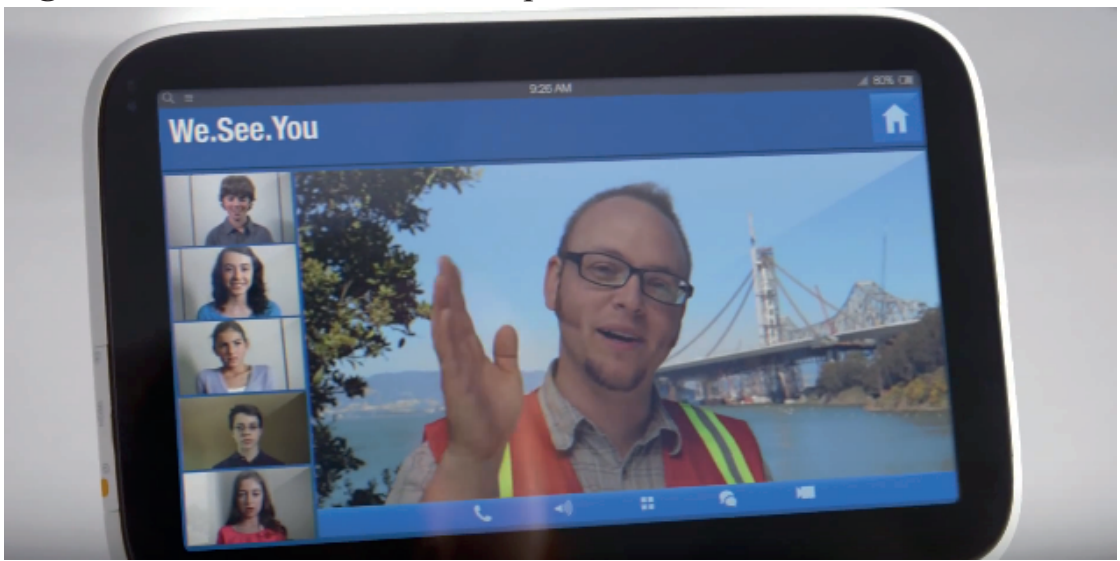

A partir da metade o vídeo, os alunos começam a parte prática do projeto da construção da ponte, elaborando e testando protótipos da ponte a ser construída (Figura 4). A partir de simulações virtuais os alunos percebem que o projeto atual não suportaria uma carga de peso. Havendo um problema a ser resolvido, os alunos discutem em grupo e com a ajuda do especialista alteram o desenho da ponte para que tenham um resultado melhor.

Figura 4: Protótipos e simulações virtuais

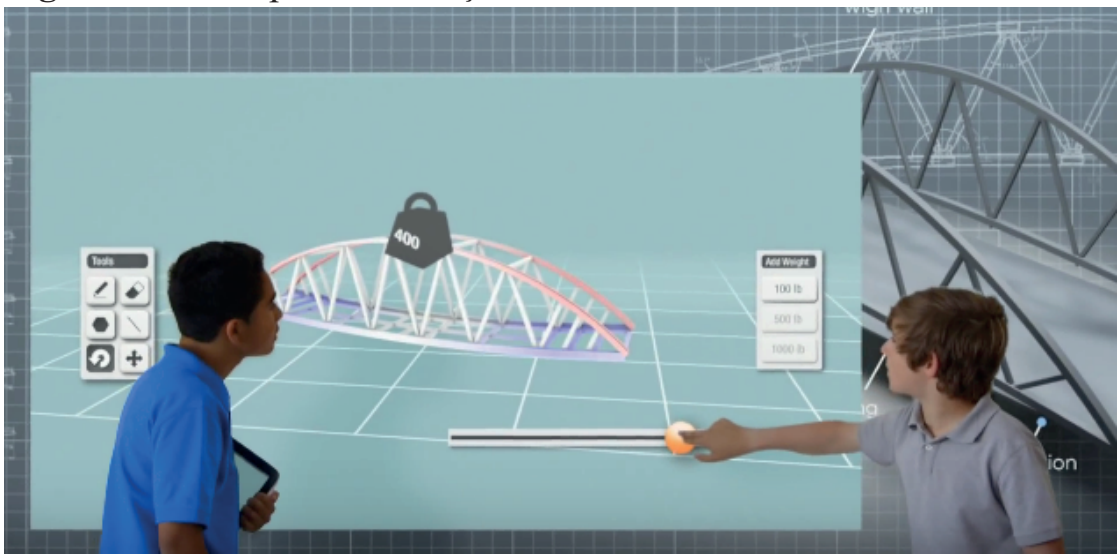


Por fim, a plataforma de ensino virtual cria as peças e, alunos e professor, utilizam de uma impressora 3D para impressão. Com o protótipo montado, os alunos testam seu projeto, simultaneamente, com outros dois grupos por meio de uma videoconferência (em uma espécie de disputa entre salas).

Figura 5: Teste de protótipos

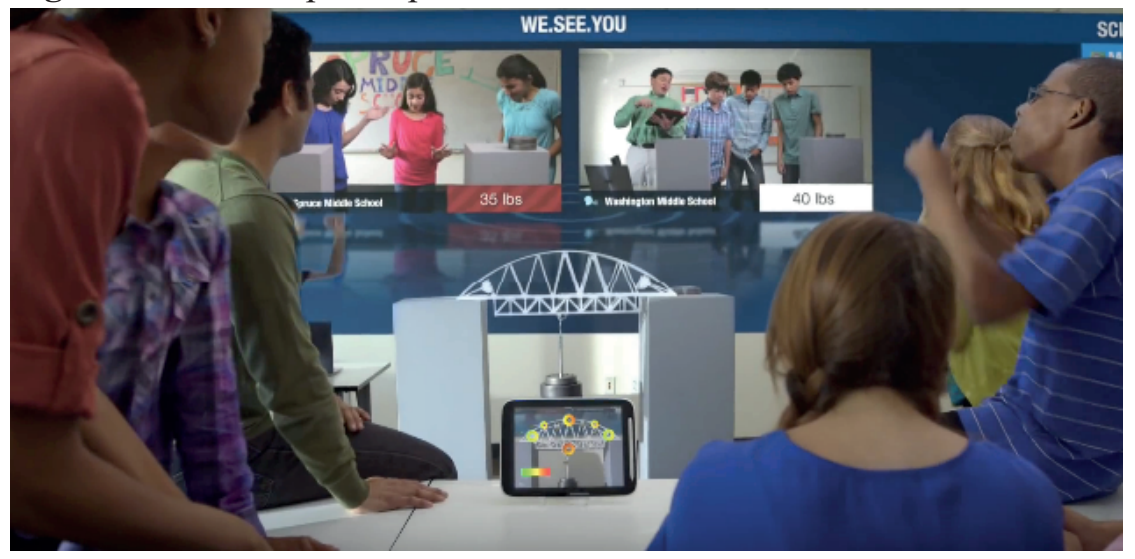

O vídeo finaliza com a assinatura da marca da Intel. Em pouco mais de 3 minutos, uma representação de como as tecnologias podem ser aplicadas dentro da escola. É possível reconhecer que o vídeo merece ser analisado sob o ponto de vista das novas tecnologias e do ensino construtivista.

\section{O ENSINO CONSTRUTIVISTA E A VISÃO DA INTEL}

Como visto, o vídeo cria uma representação da associação entre as formas de ensino. O professor pode passar o conteúdo aos alunos, havendo ensino-aprendizagem, mas possibilitando que o aluno possa interagir com o mundo físico e a sociedade, um ensino construtivista com o auxílio das novas tecnologias digitais. Os softwares educacionais e equipamentos multimídia possibilitam o interacionista-construtivista, fazendo com que o aluno tenha uma grande quantidade de informações e de recursos. 
Em um primeiro momento no audiovisual da Intel há essa associação das formas de ensino tradicionais, começando pela sala de aula: existe a lousa, o professor ensinando e os alunos sentados nas carteiras em filas, representando inicialmente uma sala de aula convencional, onde os estudantes aprendem com o conteúdo que o professor ensina. Mas, mesmo neste formato, é possível a visualização de algumas tecnologias digitais. Segundo Moran (2000, p.21), “cada vez são mais difundidas as formas de informação multimídia ou hipertextual e menos lógico-sequencial. [...] Por isso o livro se torna uma opção menos atraente; está competindo com outras mais próximas de sensibilidade deles [crianças e jovens]".

Após o conteúdo ser transmitido pelo professor, os alunos utilizam seus computadores e tablets para obterem maiores informações sobre o projeto a ser desenvolvido. O projeto pode continuar em suas respectivas casas, não se limitando à sala de aula e em interação com os pais. Como mostra no vídeo, a aluna adianta sua tarefa, interage com seu pai e, também, há a interação com o computador e o tablet, utilizados como ferramentas para construir o conhecimento através da relação com o mundo físico, social e virtual.

O papel do professor, no vídeo, também apresenta uma mudança: ele passa a ser mediador do projeto. Perrenoud (2002, p.14), defende o papel do educador como um organizador de uma pedagogia construtivista, criados de situações de aprendizagem e mediador intercultural.

É percebido, no decorrer do vídeo, que os alunos utilizam novas tecnologias digitais como tablets, computadores, internet, lousa interativa, aplicativos, impressora 3D, entre outros. Todos esses recursos sendo explorados como apoio a favor do ensino. Essas novas tecnologias digitais proporcionam um papel mais ativo dos alunos no processo de aprendizagem. A utilização de plataformas específicas, como AVA (Ambiente Virtual de Aprendizagem) dá suporte aos alunos nas atividades. Esses ambientes de aprendizagem proporcionam que o aluno aprenda e aumente seu desempenho por meio de quizzes, e possibilita o professor ter uma avaliação individual de cada aluno.

No desenvolvimento do projeto da ponte, os alunos interagiram com profissionais e outros alunos que estão à quilômetros de distância da escola, em tempo real, por vídeo conferência (como o especialista que 
tira as dúvidas dos alunos e os auxilia). Por meio dessas tecnologias, os alunos desenvolveram protótipos e testaram, a fim de melhorar os resultados do projeto.

No fim do vídeo, com o projeto da ponte finalizado, os alunos fazem uma conferência virtual com outras salas e testam seus protótipos simultaneamente. É possível reconhecer que os alunos, por meio das novas tecnologias digitais, desempenharam um papel ativo e construíram seu conhecimento para o desenvolvimento do projeto, não somente pela interação com os aparelhos, mas com plataformas e aplicativos específicos, além de profissionais e outros grupos de alunos.

É possível perceber que neste projeto os alunos tiveram noções de matemática, física e até artes e design. Segundo Betts (1998, p.26 apud MATTOS, 2010), ao inserir uma nova tecnologia educacional é importante ter um objetivo concreto:

Não podemos isolar a tecnologia do conjunto da prática educativa, porque, por si só, é burra. Existe a necessidade de intervenção de uma ação docente para que ocorra a construção do conhecimento. Nós, seres humanos, somos por natureza seres aprendentes e, conscientemente ou não, os facilitadores da construção do nosso próprio conhecimento (BETTS, 1998, p.26 apud MATTOS, 2010).

Como representado, as tecnologias não só auxiliam no aprendizado em sala de aula, mas também fora dela. Não apenas os alunos se apoiam nas tecnologias educacionais, também pode haver uma complementação nas tarefas extras dos professores, como pesquisa de conteúdos atualizados, avaliações de aprendizagem, entre outros. "O objetivo desta ferramenta é ser usada como meio e não como fim em si mesma, ou seja, ela deve ser vista como um recurso complementar e necessário" (MATTOS, 2010, p. 31).

Construir seu próprio conhecimento sobre um assunto, projeto ou conteúdo, desfrutando de recursos e tecnologias avançadas como no vídeo pode trazer um maior interesse no aluno em aprender, além de proporcionar uma nova experiência. As novas tecnologias digitais podem ser utilizadas para que o aluno tenha uma maior interação com outras pessoas e conteúdos, não se limitando apenas ao que o professor ensina, 
mas construindo seu conhecimento sobre o conteúdo e aprendendo de várias formas.

É claro que no vídeo há certa representação, de que tudo flui muito harmonicamente, os atores que atuam como alunos e professores são bem aparentados, sempre sorridentes e, na mesma medida, há uma música animada e envolvente. Porém, na prática, o uso da tecnologia nas escolas deve ser planejado, pois deve ser coordenado e ter um processo para distinguir quais ferramentas devem ser utilizados. Colocar um equipamento na mão do aluno, sem planejamento, pode ter resultados imprevisíveis, podendo haver a dispersão na aula. Por esse motivo, o professor deve saber fazer uma boa coordenação na sala de aula, em um cenário em que todos os alunos estejam conectados.

Uma sala de aula totalmente informatizada pode ser um futuro não tão distante, mas para que seja possível é necessário um grande planejamento e adequação das escolas, professores e alunos. É importante saber distinguir o que da tecnologia poderá ser utilizado, definindo quais os softwares educacionais mais recomendados para o ensino.

\section{CONSIDERAÇÕES FINAIS}

Percebe-se que as técnicas de ensino vêm mudando, desde o ensino-aprendizagem ao construtivismo e as novas tecnologias educacionais. As tecnologias digitais podem ter um papel importante na educação das crianças, desde que seja utilizada com fins pedagógicos, sob supervisão de professores e de maneira coordenada para que não traga desvantagem para as crianças.

A Intel, como empresa de tecnologia, cria este vídeo como exemplo de como as novas tecnologias podem ser utilizadas na aplicação de um ensino interacionista-construtivista. Claro que para que o audiovisual seja a representação de um futuro real há a necessidade de investimento das escolas em recursos tecnológicos e, principalmente, na capacitação dos professores com planejamento de suas metodologias de ensino.

Os educadores devem proporcionar a interação dos alunos com as novas tecnologias educacionais digitais, de forma que seja um apoio para a educação e que tragam benefícios para os alunos e professores.

É certo que a introdução da tecnologia nas salas de aula deve 
ser bem planejada e coordenada, começando aos poucos e ir evoluindo, não somente dando um tablet para cada aluno, mas sabendo lidar com isso, estando preparados para a nova realidade que a tecnologia traz na educação.

\section{REFERÊNCIAS}

ANDRADE, L. et al. Jogos inteligentes são educacionais? In: SBIE SIMPÓSIO BRASILEIRO DE INFORMÁTICA NA EDUCAÇÃO: INCLUSÃO DIGITAL COMO INSTRUMENTO DE INCLUSÃO SOCIAL, 14., 2003, Rio de Janeiro. Anais... Rio de Janeiro, 2003. p. 699-707.

BRASIL. Ministério da Educação. Guia de tecnologias educacionais. Brasília, 2008. Disponível em: <http://portal.mec.gov.br/seb/arquivos/ pdf/Avalmat/guia_de_tecnologias_educacionais.pdf $>$. Acesso em: 23 out. 2016.

CARVALHO, A. Tecnologia no ensino infantil: crianças pequenas também usam computador, telefone, ipad e outras ferramentas. Como isso afeta a aprendizagem? Disponível em: $<$ http://educarparacrescer. abril.com.br/comportamento/tecnologia-ensino-infantil-724672.shtml $>$. Acesso em: 22 out. 2016.

INTEL. Intel education: free taching resources, tools. Disponível em: $<$ http://www.intel.com.br/content/www/br/pt/education/k12/teachers. html>. Acesso em: 3 fev. 2017.

. Project Bridge - a visão da Intel para educação. 2013.

Disponível em: <https:/www.youtube.com/watch?v=cfRya2Hmlao>. Acesso em: 15 dez. 2016.

LEÃO, D. M. M. Paradigmas contemporâneos de educação: escola tradicional e escola construtivista. Cadernos de Pesquisa, n. 107, p. 187-206, jul. 1999.

LEITE, S. M.; MORESCO, S. F. S.; BEHAR, P. A. A interação de 
crianças e adolescentes em ambientes virtuais: identificando fatores de acessibilidade e navegabilidade. In: SIMPÓSIO BRASILEIRO DE INFORMÁTICA NA EDUCAÇÃO: METODOLOGIAS, TECNOLOGIAS E APRENDIZAGEM DENTRO DO CENÁRIO DA INFORMÁTICA NA EDUCAÇÃO, 13., 2002, São Leopoldo. Anais... São Leopoldo: Unisinos, 2002. p. 210-219.

MATTOS, Cristiane Millan de. A escola como espaço de inclusão digital. 2010. Disponível em: <http://monografias.brasilescola.com/ matematica/a-escola-como-espaco-inclusao-digital.htm $>$. Acesso em: 13 jun. 2015.

MORAN, J. M. Ensino e aprendizagem inovadores com tecnologias audiovisuais e telemáticas. In: MORAN, J. M.; MASETTO, M. T.; BEHRENS, M. A. P. Novas tecnologias e mediação pedagógica. Campinas: Papirus, 2000. p.11-65.

PERRENOUD, Philippe. A prática reflexiva no ofício do professor: profissionalização e razão pedagógica. Porto Alegre: Artmed, 2002.

PINTO, S. C. C. S. et al. AVA: um ambiente virtual baseado em comunidades. In: SIMPÓSIO BRASILEIRO DE INFORMÁTICA NA EDUCAÇÃO: METODOLOGIAS, TECNOLOGIAS E APRENDIZAGEM DENTRO DO CENÁRIO DA INFORMÁTICA NA EDUCAÇÃO. 13., 2002, São Leopoldo. Anais... São Leopoldo: Unisinos, 2002. p. 31-38.

SCHNEIDER, H. N. A escola como uma organização de aprendizagem interativa informatizada. In: SIMPÓSIO BRASILEIRO DE INFORMÁTICA NA EDUCAÇÃO: METODOLOGIAS, TECNOLOGIAS E APRENDIZAGEM DENTRO DO CENÁRIO DA INFORMÁTICA NA EDUCAÇÃO, 13., 2002, São Leopoldo. Anais... São Leopoldo: Unisinos, 2002. p. 136-145. 